\title{
Association Between Mental Health and Oral Health Status and Care Utilization
}

\author{
Tamanna Tiwari ${ }^{*}$, Abigail Kelly ${ }^{2}$, Cameron L. Randall ${ }^{3}$, Eric Tranby ${ }^{2}$ and \\ Julie Franstve-Hawley ${ }^{2}$
}

\begin{abstract}
${ }^{1}$ School of Dental Medicine, University of Colorado Anschutz Medical Campus, Aurora, CO, United States, ${ }^{2}$ CareQuest Institute for Oral Health, Boston, MA, United States, ${ }^{3}$ Department of Oral Health Sciences, University of Washington School of Dentistry, Seattle, WA, United States
\end{abstract}

Studies have shown that mental health and oral health may be correlated, with associations demonstrated between mental health problems and tooth loss, periodontal disease, and tooth decay. The COVID-19 pandemic had alarming implications for individuals' and communities' mental and emotional health. This study examined the associations between mental health status, oral health status, and oral healthcare utilization and highlighted the impact of COVID-19 on mental health. Additionally, this study examines specific sociodemographic factors that may amplify oral health disparities. A nationally representative survey was conducted to capture attitudes,

OPEN ACCESS

Edited by:

Gustavo G. Nascimento, Aarhus University, Denmark

Reviewed by:

Noha Gomaa,

Western University, Canada Sonia Nath

University of Adelaide, Australia

*Correspondence:

Tamanna Tiwari

tamanna.tiwari@cuanschutz.edu

Specialty section:

This article was submitted to

Oral Health Promotion,

a section of the journal

Frontiers in Oral Health

Received: 29 June 2021 Accepted: 09 December 2021 Published: 07 February 2022

Citation:

Tiwari T, Kelly A, Randall CL, Tranby E and Franstve-Hawley J (2022)

Association Between Mental Health and Oral Health Status and Care

Utilization.

Front. Oral. Health 2:732882.

doi: 10.3389/froh.2021.732882 experiences, and behaviors related to oral health, mental health, and unmet oral health needs. Eighteen percent of respondents were categorized as having poor mental health. Visiting the dentist in the last year was more common amongst individuals with good mental health. From the logistic regression model, mental health status, age group, race/ethnicity, education, and last dental visit were all significantly associated with of oral health status. Mental health status, age group, and income groups were all significantly associated with unmet oral health need. Future work should focus on the mental-oral health association, including determining ways to improve oral healthcare utilization and oral health status among people with poorer mental health.

Keywords: mental health, oral health, stress, anxiety, psychology, values

\section{INTRODUCTION}

Individuals with mental illnesses are more likely than those without to have suboptimal oral health [1]. Although the nature of this relationship has not been extensively evaluated, a few studies have shown a relationship between oral health and mental health, or vice versa [2-4].

One systematic review has addressed the association between poor oral health and common psychological disorders (e.g., a diagnosis of depression, generalized anxiety disorder, panic disorder, obsessive-compulsive disorder, post-traumatic stress disorder, or a phobia) [2]. The study demonstrated a significant association between common mental health disorders and tooth loss; individuals with common psychological disorders had higher rates of decayed, missing, and filled teeth surfaces than controls. Overall, the researchers concluded that the rates of dental decay and tooth loss were higher for patients with common mental disorders as compared to the general population [2]. Other studies have shown a relationship between poor oral health (e.g., chronic periodontitis, tooth erosion) and severe mental illness and eating disorders [3, 4]. 
In patients with depression and anxiety, past research documented the association between the use of oral health services and tooth loss [5]. Many depressive symptoms, such as anhedonia or lack of motivation, feelings of worthlessness, and fatigue, may adversely affect adults' behaviors related to oral hygiene maintenance [5]. Several studies demonstrated similar results related to depression, dental behaviors, and the management of dental diseases such as periodontal disease [68]. These studies highlight the public health implications of mental health on oral health outcomes and the potential cycle of relationship oral health has with mental health (and vice versa). Greater risk for dental decay and tooth loss can lead to more frequent pain experience, social isolation, and low self-esteem, and reducing quality of life and in turn possibly being associated with poorer mental and overall health [9].

The COVID-19 pandemic had alarming implications for individuals' and communities' mental and emotional health [10]. Factors including isolation and feelings of uncertainty negatively impacted mental health and included effects such as increased anxiety, loneliness, depression, insomnia, and in some cases, selfharm [10]. A large portion of the population experienced job loss and economic difficulties exacerbated mental health issues $[11,12]$.

The pandemic took a toll on oral health as well: dental practices were closed for a long period of time, elective dental procedures were postponed, and access to preventive care was delayed [13]. Many groups were disproportionately affected by the pandemic, including populations with a higher risk for poor oral health, those with other chronic diseases and comorbidities, low socioeconomic groups, and minority populations [14]. Although several studies reviewed the relationship between the pandemic and mental or oral health individually, none have examined the association between mental and oral health during the pandemic [11-14]. This study aimed to identify the associations between mental health, oral health, and oral healthcare utilization during the COVID-19 pandemic as well as specific sociodemographic factors that may amplify disparities.

\section{METHODS}

A nationally representative cross-sectional survey $(n=5,320)$ was conducted in January and February 2021 to assess consumer attitudes, experiences, and behaviors related to oral health. This study was deemed exempt by the WCG IRB.

The survey called the State of Oral Health Equity in America 2021 contained items related to oral health knowledge, dental care experiences, interprofessional care, insurance, and social determinants of health. The survey included $\sim 150$ questions. The questions were developed by an internal team at the CareQuest Institute comprised of knowledge experts on payer, provider, and patients' experiences with oral health.

The survey was administered to adults 18 years and older by the non-partisan research organization National Opinion Research Center (NORC) at the University of Chicago, using the AmeriSpeak panel. AmeriSpeak is a probability-based panel designed to be representative of the U.S. household population.
Randomly selected U.S. households were sampled using area probability and address-based sampling, with a known, non-zero probability of selection from the NORC National Sample Frame. Sampled households were contacted by U.S. mail, telephone, and field interviewers. The survey was internally piloted at CareQuest Institute, as well as initially piloted by NORC on a sample size of 500. A sampling unit of 16,986 was used with a final sample size or weight sample was 5,320 with a final weighted cumulative response rate of 5.2\%. All data presented account for appropriate sample weights. This sample size was decided in collaboration with NORC in order to obtain a margin of error of under 2 while having sufficient sub-sample sizes. The margin of error for this survey is $1.86 \%$.

Self-rated mental health items asked that participants be asked to rate their mental health as excellent, very, good, good, fair, and poor, and for the analysis, it was dichotomized to poor (fair, poor) or good (excellent, very good, good). Self-rated oral health status (dependent variable) asked participants to rate their oral health status as either excellent, very, good, good, fair, and poor. Unmet oral health needs (dependent variable) were a dichotomized variable and asked if the participant had unmet needs (yes/no). The information on unmet needs was collected by asking the respondents, "have you had an unmet oral health need in the last year?" The survey also collected information on several independent variables, including, participants' age, gender, race/ethnicity, household income, education, if they live in metro or non-metro areas, and health insurance coverage. Other oral health-related questions included the last visit to the dentist and if the participants had dental insurance.

Descriptive statistics were conducted to summarize the percent and frequencies for the independent variables. Data are presented by unweighted frequencies and weighted percentages. Bivariate analyses were run to examine relationships between self-rated mental health status and oral health status and unmet need by age group, income, race/ethnicity, and gender using Chi-Square tests. Multivariable logistic regression models were used for each outcome of interest, including a respondent's selfrated oral health status and having unmet oral health needs. Covariables included self-rated mental health, age group, gender, income group, race/ethnicity, education level, metro/non-metro, occurrence of last dental visit, health insurance status, and dental insurance status. All variables of interest were included in the model, and those with $p$-values of $<0.05$ were considered significant. Appropriate weights were applied to all analyses. Additional analyses included examining COVID-19 effects on life changes and mental health and oral health care utilization. COVID-19 life changes were examined by asking if individual events had occurred for a respondent within the last year, and cross-tabulated with the dichotomized mental health selfassessment variable.

\section{RESULTS}

Table 1 describes the mental health status of the entire sample. Those with poor mental health were disproportionately affected by life changes since the COVID-19 pandemic began. About 
TABLE 1 | Mental health and COVID from the State of Oral Health Equity Survey $2021(n=5,296)$.

\begin{tabular}{|c|c|c|c|}
\hline & $\begin{array}{c}\text { Good mental } \\
\text { health } 4,379 \\
(81.9 \%)\end{array}$ & $\begin{array}{c}\text { Poor mental } \\
\text { health } 917 \\
(18.1 \%)\end{array}$ & $p$-value* \\
\hline $\begin{array}{l}\text { Covid life changes } \\
\text { Job related variables } \\
\text { Lost Job }\end{array}$ & $461(10.8 \%)$ & 159 (16.1\%) & 0.0007 \\
\hline Started a new job did not like & $112(2.9 \%)$ & $55(6.7 \%)$ & $<0.0001$ \\
\hline Started a new job you liked & $281(6.7 \%)$ & $90(9.7 \%)$ & 0.0242 \\
\hline $\begin{array}{l}\text { Taken a new job below your } \\
\text { education }\end{array}$ & 148 (3.3\%) & $56(6.6 \%)$ & 0.0008 \\
\hline Taken an additional Job & $154(3.3 \%)$ & $48(4.0 \%)$ & 0.3805 \\
\hline Been worried to lose your job & 445 (10.8\%) & 152 (15.6\%) & 0.0016 \\
\hline $\begin{array}{l}\text { Home related variables } \\
\text { Missed rent or mortgage }\end{array}$ & $306(7.5 \%)$ & $135(14.5 \%)$ & $<0.0001$ \\
\hline Been threatened with foreclosure & 98 (2.1\%) & $66(7.3 \%)$ & $<0.0001$ \\
\hline Bought a home & $173(3.8 \%)$ & $30(3.5 \%)$ & 0.7186 \\
\hline Had to move & $214(5.1 \%)$ & 95 (9.7\%) & $<0.0001$ \\
\hline Study sample characteristics & & & 0.0191 \\
\hline \multicolumn{4}{|l|}{ Gender } \\
\hline Female & 2052 (50.4\%) & $532(56.3 \%)$ & \\
\hline Male & 2327 (49.6\%) & 385 (43.7\%) & \\
\hline Age group & & & $<0.0001$ \\
\hline $18-29$ & $560(17.5 \%)$ & $231(35.0 \%)$ & \\
\hline $30-44$ & 1196 (25.0\%) & 307 (25.1\%) & \\
\hline $45-59$ & $923(24.8 \%)$ & 199 (22.5\%) & \\
\hline $60+$ & $1700(32.6 \%)$ & $180(17.5 \%)$ & \\
\hline Race/ethnicity & & & 0.3684 \\
\hline Asian & 97 (5.0\%) & $13(4.4 \%)$ & \\
\hline Black & $646(12.0 \%)$ & $118(11.6 \%)$ & \\
\hline $2+$ & $115(2.3 \%)$ & $41(3.4 \%)$ & \\
\hline Hispanic & $748(16.0 \%)$ & 199 (19.5\%) & \\
\hline Other & $63(1.4 \%)$ & $13(0.9 \%)$ & \\
\hline White & 2710 (63.4\%) & $533(60.2 \%)$ & \\
\hline Household income & & & $<0.0001$ \\
\hline Less than $\$ 30,000$ & 1066 (24.9\%) & $380(41.8 \%)$ & \\
\hline$\$ 30,000-\$ 60,000$ & 1236 (25.9\%) & 262 (27.0\%) & \\
\hline$\$ 60,000-\$ 100,000$ & 1157 (25.2\%) & $172(17.9 \%)$ & \\
\hline$\$ 100,000$ or more & $920(24.0 \%)$ & 103 (13.4\%) & \\
\hline Education & & & $<0.0001$ \\
\hline Less than HS & $196(8.8 \%)$ & $63(14.3 \%)$ & \\
\hline HS graduate or equivalent & $806(26.3 \%)$ & 211 (34.9\%) & \\
\hline Some college/associates degree & $2103(27.3 \%)$ & 459 (29.4\%) & \\
\hline Bachelor's degree & $746(21.8 \%)$ & $131(14.3 \%)$ & \\
\hline Post graduate study & $528(15.8 \%)$ & $53(7.1 \%)$ & \\
\hline Region & & & 0.4633 \\
\hline Non-metro area & 697 (16.5\%) & 165 (17.8\%) & \\
\hline Metro area & 3682 (83.5\%) & 752 (82.2\%) & \\
\hline Last dental visit & & & $<0.0001$ \\
\hline Less than 6 months ago & 1931 (44.9\%) & $300(30.8 \%)$ & \\
\hline Between 6 months to 1 year ago & 885 (19.9\%) & 171 (18.5\%) & \\
\hline $\begin{array}{l}\text { More than a year and less than two } \\
\text { years ago }\end{array}$ & 690 (15.3\%) & 162 (17.7\%) & \\
\hline $\begin{array}{l}\text { More than } 2 \text { and less than } 5 \text { years } \\
\text { ago }\end{array}$ & 480 (11.1\%) & 138 (14.1\%) & \\
\hline
\end{tabular}

(Continued)
TABLE 1 | Continued

\begin{tabular}{|c|c|c|c|}
\hline & $\begin{array}{c}\text { Good mental } \\
\text { health } 4,379 \\
(81.9 \%)\end{array}$ & $\begin{array}{c}\text { Poor mental } \\
\text { health } 917 \\
(18.1 \%)\end{array}$ & $p$-value * \\
\hline 5 or more years ago & 352 (7.4\%) & $136(16.8 \%)$ & \\
\hline Never & $37(1.5 \%)$ & $10(2.1 \%)$ & \\
\hline Dental insurance status & & & 0.1245 \\
\hline Insured & 3049 (70.5\%) & $622(67.0 \%)$ & \\
\hline Not insured & $1314(29.5 \%)$ & 293 (33.0\%) & \\
\hline Health insurance status & & & 0.0427 \\
\hline Insured & 3998 (91.2\%) & 804 (88.1\%) & \\
\hline Not insured & 368 (8.8\%) & 107 (11.9\%) & \\
\hline Oral health status & & & $<0.0001$ \\
\hline Excellent & $324(8.4 \%)$ & $18(2.7 \%)$ & \\
\hline Very good & 1418 (32.7\%) & $89(9.5 \%)$ & \\
\hline Good & $1726(39.6 \%)$ & $277(28.7 \%)$ & \\
\hline Fair & $683(14.5 \%)$ & $357(41.0 \%)$ & \\
\hline Poor & 217 (4.6\%) & $174(18.0 \%)$ & \\
\hline Unmet needs & & & $<0.0001$ \\
\hline Yes & $2312(52.8 \%)$ & $651(69.2 \%)$ & \\
\hline No & 2067 (47.2\%) & $266(30.8 \%)$ & \\
\hline Oral health symptoms treatment & & & $<0.0001$ \\
\hline Went to the dentist & $1019(44.5 \%)$ & $218(30.6 \%)$ & \\
\hline Went to the ED & $36(1.8 \%)$ & $18(2.8 \%)$ & \\
\hline Did nothing & 1249 (53.4\%) & 412 (66.3\%) & \\
\hline
\end{tabular}

"All variables are reported at weighted $n$ (unweighted \%); $p$-value results from Chi-square test.

$16 \%$ of respondents with poor mental health had lost their job, compared to $11 \%$ with good mental health $(p=0.0007)$. Those with poor mental health were also $5 \%$ more likely to be worried about losing their current job $(p=0.0016)$. Compared to those with good mental health, those with poor mental health were twice ( 14.5 vs. $7.5 \%, p<0.0001)$ as likely to have missed a mortgage payment. Since the pandemic began $5 \%$ of the respondents will poor mental health more likely to have been threatened with eviction or foreclosure ( 2 vs. $7 \%, p<0.0001$ ), and had to move at double the rate ( 5 vs. $10 \%, p<0.0001$ ).

Table 1 also provides the description of the overall sample is provided. Eighteen percent of respondents rated their mental health as poor, and $82 \%$ rated it as good. Females were $4 \%$ more likely to rate their mental health as poor compared to men (20 vs. $16 \%, p=0.0191$ ). About $35 \%$ of respondents age $18-$ 29 years reported poor mental while only $17 \%$ reported good mental health. Those who had poor mental health were over three times more likely to rate their oral health as poor compared to those with good mental health (18 vs. $4.6 \%, p<0.0001$ ). Those who had poor mental health were less likely to be insured compared to those who reported good mental health (88 vs. $91 \%$, $p<0.0001$ ). Sixty-nine percent of respondents with poor mental health reported having one or more unmet oral health needs compared to $53 \%$ of those with good mental health reporting the same $(p<0.0001)$. Of those who had an unmet oral health need, those with self-rated good mental health were much more likely 
to seek care. Forty-five percent of respondents with good mental health said they visited the dentist to address their symptoms; $2 \%$ said they went to the emergency department (E.D.) and 53\% said they did nothing. Only $31 \%$ of respondents with poor mental health went to a dentist to address their symptoms; $3 \%$ went to the E.D., and 66\% did nothing $(p<0.0001)$.

Table 2 provides the results of the logistic regression model oral health status. Respondents with self-rated good mental health had low odds of rating their oral health as "poor" (OR = 0.22 ; $95 \% \mathrm{CI}=0.18,0.26)$. Respondents aged $45-59$ years had high odds of rating their oral health as 'poor' (OR $=1.2095 \% \mathrm{CI}$ $=1.0,1.4)$. Respondents who self -reported belonging to more than two races were more likely to rate their oral health as poor $(\mathrm{OR}=1.33$ 95\% CI $=0.91,1.94)$.

The odds of respondents rating their oral health as "poor" decreased with increased levels of education (H.S. graduate or equivalent $\mathrm{OR}=0.89,95 \% \mathrm{CI}=0.66,1.20$; Vocational $/$ tech school/some college/associates $\mathrm{OR}=0.88,95 \% \mathrm{CI}=0.67,1.18$; Bachelor's degree OR $=0.75,95 \% \mathrm{CI}=0.55,1.02$; Postgrad study/professional degree $\mathrm{OR}=0.59,95 \% \mathrm{CI}=0.42,0.83$ ).

In addition, respondents who had an income of over $\$ 30,000$ had lower odds of rating their oral health as "poor" and as the income increased the odds decreased $(\$ 30,000$ to under $\$ 60,000$, OR 0.96; $\$ 60,000$ to under $\$ 100,000$, OR $=0.69 ; \$ 100,000$ or more $\mathrm{OR}=0.55)$ Respondents who had visited the dentist in the last 6 months $(\mathrm{OR}=0.65,95 \% \mathrm{CI}=0.31,1.31)$ and between 6 months and a year $(\mathrm{OR}=0.97,95 \% \mathrm{CI}=0.48,1.99)$ had lower odds of rating their oral health as "poor."

Table 3 provides the results of the logistic regression model for unmet oral health needs. Respondents with self-rated good mental health had low odds of having an unmet oral health need $(\mathrm{OR}=0.55,95 \% \mathrm{CI}=0.45,0.69)$. Those in the highest two income groups ( $\$ 60,000$ to under $\$ 100,000, \mathrm{OR}=0.0 .76,95 \% \mathrm{CI}$ $=0.88,1.31 ; \$ 100,000$ or more, $\mathrm{OR}=0.76,95 \% \mathrm{CI}=0.59,0.97)$ had low odds of having an unmet oral health need. Respondents aged $30-44$ years $(\mathrm{OR}=1.2795 \% \mathrm{CI}=1.05,1.53)$ and $45-59$ years $(\mathrm{OR}=1.3595 \% \mathrm{CI}=1.11,1.65)$ had high odds of rating their oral health as "poor."

\section{DISCUSSION}

This is the first study to evaluate the relationship between oral health and mental health during the COVID-19 pandemic and contributes to a larger but still underdeveloped body of literature on the association between oral and mental health, generally. Our survey of a representative sample of U.S. households found that about $20 \%$ of respondents reported poor mental health. About $35 \%$ of younger respondents (i.e., aged 18-25 years) and $43 \%$ of females reported poor mental health. Respondents with low income and less education also reported poor mental health. Respondents who reported poor mental health were more likely to be facing financial and emotional hardships and were more likely to have had COVID-19.

Our results are consistent with national statistics. According to the National Alliance on Mental Illness and the National Institute of Mental Health, $21 \%$ of all adults report poor mental health in the U.S. annually [15]. The National Institute of Mental Health also reports that the prevalence of mental illness is higher in females compared to males and that young adults aged $18-25$ years have the highest prevalence $(30 \%)$ of any mental illness compared to all other age groups [15, 16]. Given that our data were collected during the COVID-19 pandemic, we used a probability-based panel and our results were consistent with national data, our results are reliable to make national level conclusions.

Poor oral health status among the respondents was associated with poor mental health, age, socioeconomic status, and not visiting the dentist at regular intervals. There is much evidence that socioeconomic status is closely associated with oral health status, irrespective of the socioeconomic measure used [17, 18]. A recent National Health and Nutrition Examination Survey study reported that age, race/ethnicity, education, and family income were significantly associated with the oral health status of Americans [18]. In this study, whites rated their oral health as poor more often compared to those from other racial groups. These results are similar to those from previous studies which have found that racial minorities perceive less need for oral health services and have lower health literacy, thus often not rating their oral health as poor $[19,20]$.

There is a paucity of research on the association between poor mental health and poor oral health status. However, a few studies in this area shed light on possible underlying reasons for this association. Low prioritization of oral health, low recognition of the association between poor oral and mental health by healthcare providers, and lack of alternative service models in dental settings for those with heightened fear and anxiety and/or mental health problems have been identified as some of the underlying reasons for this association $[1,2]$.

Unmet oral health needs of the respondents were associated with poor mental health, income, and utilization of dental care. Over $65 \%$ of the respondents who endorsed poor mental health reported doing nothing about their oral health symptoms. Evidence suggests that individuals who have experienced a mental health disorder underutilize dental services. Reasons such as stigma, shame, helplessness, low self-esteem, lack of income and health insurance, dental fear/anxiety/phobia, and restlessness in the dental waiting environment contribute to underutilization $[21,22]$. In addition, individuals who have experienced a mental health disorder may have confusion and difficulty recalling instructions, fostering mistrust between dental providers and patients [21, 23]. Also, individuals with poor mental health are more likely to belong to low-socioeconomic groups, be unemployed, and have substantial comorbidities, and these factors could contribute to and exacerbate the underutilization of dental services [24]. Other essential aspects of underutilization of dental care among individuals with mental health issues are perceived need for treatment, motivation to visit the dentist, and social and physical environmental barriers such as clinic location, the flexibility of the providers, and clinic hours [25]. Apart from patient-level factors, structural, organizational, and environmental factors such as limited specialized expertise of oral health providers in working with patients with mental health problems as well as lack of interprofessional integration between 
TABLE 2 | Association between Oral Health Status and Mental Health from the State of Oral Health Equity in America survey 2021.

\begin{tabular}{|c|c|c|c|c|}
\hline & Odds ratio & & $95 \%$ confidence limits & $p$-value* \\
\hline & & & & \\
\hline Poor & 1.00 & & & \\
\hline Good & 0.22 & 0.18 & 0.26 & \\
\hline Gender & & & & 0.1691 \\
\hline Male & 1.00 & & & \\
\hline Female & 0.91 & 0.80 & 1.0 & \\
\hline Age group & & & & 0.0002 \\
\hline $60+$ & 1.00 & & & \\
\hline $18-29$ & 0.73 & 0.59 & 0.89 & \\
\hline $30-44$ & 0.92 & 0.78 & 1.09 & \\
\hline $45-59$ & 1.20 & 1.00 & 1.44 & \\
\hline Race/ethnicity & & & & 0.0046 \\
\hline White, non-Hispanic & 1.00 & & & \\
\hline 2+, non-Hispanic & 1.33 & 0.91 & 1.94 & \\
\hline Asian, non-Hispanic & 0.99 & 0.668 & 1.48 & \\
\hline Black, non-Hispanic & 0.93 & 0.76 & 1.15 & \\
\hline Hispanic & 0.78 & 0.65 & 0.94 & \\
\hline Other, non-Hispanic & 0.43 & 0.24 & 0.79 & \\
\hline Education level & & & & 0.0024 \\
\hline Less than HS & 1.00 & & & \\
\hline HS graduate or equivalent & 0.89 & 0.66 & 1.20 & \\
\hline $\begin{array}{l}\text { Vocational/tech school/some } \\
\text { college/associates }\end{array}$ & 0.88 & 0.67 & 1.18 & \\
\hline Bachelor's degree & 0.75 & 0.55 & 1.02 & \\
\hline Post grad study/professional degree & 0.59 & 0.42 & 0.83 & \\
\hline Income group & & & & $<0.0001$ \\
\hline Less than $\$ 30,000$ & 1.00 & & & \\
\hline$\$ 30,000$ to under $\$ 60,000 \mathrm{v}$ & 0.96 & 0.80 & 1.16 & \\
\hline$\$ 60,000$ to under $\$ 100,000$ & 0.69 & 0.57 & 0.84 & \\
\hline$\$ 100,000$ or more & 0.55 & 0.45 & 0.68 & \\
\hline Metro & & & & 0.5041 \\
\hline Non-metro area & 1.00 & & & \\
\hline Metro area & 0.94 & 0.79 & 1.12 & \\
\hline Last dental visit & & & & $<0.0001$ \\
\hline Never & 1.00 & & & \\
\hline Less than 6 months ago & 0.65 & 0.317 & 1.31 & \\
\hline Between 6 months ago and one year ago & 0.97 & 0.48 & 1.99 & \\
\hline $\begin{array}{l}\text { More than a year and less than two years } \\
\text { ago }\end{array}$ & 1.56 & 0.77 & 3.17 & \\
\hline More than 2 and less than 5 years ago & 2.64 & 1.29 & 5.40 & \\
\hline 5 or more years ago & 5.05 & 2.47 & 10.34 & \\
\hline Health insurance status & & & & 0.2381 \\
\hline Yes & 1.00 & & & \\
\hline No & 1.16 & 0.91 & 1.49 & \\
\hline Dental insurance status & & & & 0.1038 \\
\hline Yes & 1.00 & & & \\
\hline No & 0.87 & 0.74 & 1.03 & \\
\hline
\end{tabular}

"Multivariable logistic regression. 
TABLE 3 | Association between Unmet Oral Health Needs and Mental Health from the State of Oral Health Equity in America survey 2021.

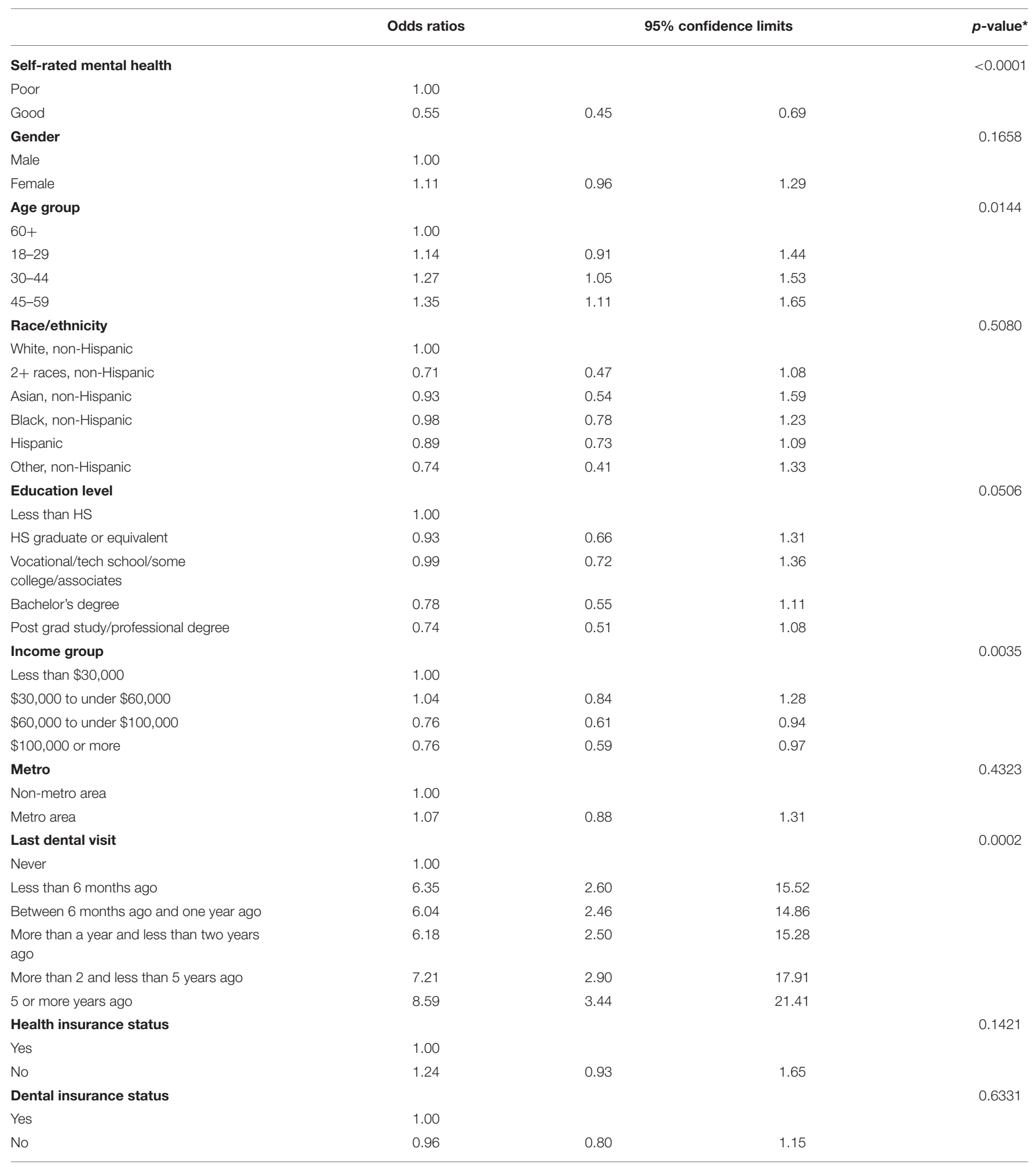

"Multivariable logistic regression. 
dental services and general medical and mental health services can exacerbate the underutilization [25].

Our study has some limitations. The results of the survey are based on a cross-sectional survey, and all data were selfreported by the participants. Though there are numerous selfreport instruments validated for the assessment of specific mental health problems, the time and space limitations of the overall survey design limited the number of mental health-related items that could be included. Thus, only a single item assessing general mental health was used. We plan to collect similar data in 2022 to keep the research continuum and work toward better understanding the relationship between mental and oral health over time. Future studies will utilize more specific validated measures because the mental health variable lacked specificity (as it did not provide diagnostic-level information). Despite these limitations, this study offers a significant contribution to the literature, highlighting the association between oral health status and poor mental health at the population level. Further research is necessary to understand the mechanisms underlying these associations and develop models of care that will promote oral health utilization by individuals with mental health problems.

\section{DATA AVAILABILITY STATEMENT}

The datasets presented in this article are not readily available because the raw dataset for this study is the property of the CareQuest Institute for Oral Health. A request needs to be submitted to the corresponding author to get access to the

\section{REFERENCES}

1. Scrine C, Durey A, Slack-Smith L. Enhancing oral health for better mental health: exploring the views of mental health professionals. Int J Mental Health Nurs. (2018) 27:178-86. doi: 10.1111/inm.12307

2. Kisely S, Baghaie H, Lalloo R, Siskind D, Johnson NW. A systematic review and meta-analysis of the association between poor oral health and severe mental illness. Psychosomatic Med. (2015) 77:83-92. doi: 10.1097/PSY.0000000000000135

3. Kisely S, Baghaie H, Lalloo R, Johnson NW. Association between poor oral health and eating disorders: systematic review and meta-analysis. $\mathrm{Br} \mathrm{J}$ Psychiatry. (2015) 207:299-305. doi: 10.1192/bjp.bp.114.156323

4. de Oliveira Solis AC, Marques AH, Dominguez WV, de Almeida Prado EB, Pannuti CM, Lotufo RFM, et al. Evaluation of periodontitis in hospital outpatients with major depressive disorder. A focus on gingival and circulating cytokines. Brain Behav Immunity. (2016) 53:4953. doi: 10.1016/j.bbi.2015.11.014

5. Okoro CA, Strine TW, Eke PI, Dhingra SS, Balluz LS. The association between depression and anxiety and use of oral health services and tooth loss. Community Dentistry Oral Epidemiol. (2012) 40:134-44. doi: 10.1111/j.1600-0528.2011.00637.x

6. Rosania AE, Low KG, McCormick CM, Rosania DA. Stress, depression, cortisol, and periodontal disease. J Periodontol. (2009) 80:260-6. doi: 10.1902/jop.2009.080334

7. Sisko Anttila S, Knuuttila MLE, Sakki TK. Relationship of depressive symptoms to edentulousness, dental health, and dental health behavior. Acta Odontol Scand. (2001) 59:406-12. doi: 10.1080/000163501317153275

8. Anttila S, Knuuttila M, Ylöstalo P, Joukamaa M. Symptoms of depression and anxiety in relation to dental health behavior and self-perceived dental treatment need. Euro J Oral Sci. (2006) 114:109-14. doi: 10.1111/j.1600-0722.2006.00334.x raw data. Requests to access the datasets should be directed to tamanna.tiwari@cuanschutz.edu.

\section{ETHICS STATEMENT}

This study was deemed exempt by the WCG IRB. Written informed consent for participation was not required for this study in accordance with the national legislation and the institutional requirements.

\section{AUTHOR CONTRIBUTIONS}

TT, AK, CR, ET, and JF-H contributed to the conception and design, data analysis and interpretation, drafted, and critically revised the manuscript. Data acquisition was done by AK, ET, and JF-H. All authors gave final approval and agree to be accountable for all aspects of the work.

\section{FUNDING}

CR received support from Grant K23DE028906 in preparation of the manuscript.

\section{ACKNOWLEDGMENTS}

Madhuli Thakkar, BDS, MPH for help in data analysis, and code validation.

9. Gift HC, Atchison KA. Oral health, health, and health-related quality of life. Medical care. (1995) NS57-77. doi: 10.1097/00005650-19951100 $1-00008$

10. Pfefferbaum B, North CS. Mental health and the Covid-19 pandemic. N Engl J Med. (2020) 383:510-2. doi: 10.1056/NEJMp2008017

11. Organization W.H. Mental Health and Psychosocial Considerations During the COVID-19 Outbreak, March 18th 2020. World Health Organization (2020). Available online at: https://www.who.int/publications/i/item/WHO-2019nCoV-MentalHealth-2020.1

12. Kumar A, Nayar KR. COVID 19 and its mental health consequences. J Mental Health. (2020) 180:817-8. doi: 10.1001/jamainternmed.2020.1562

13. Ren Y, Rasubala L, Malmstrom H, Eliav E. Dental care and oral health under the clouds of COVID-19. JDR Clin Transl Res. (2020) 5:20210. doi: $10.1177 / 2380084420924385$

14. Zachary BD, Weintraub JA. Oral health and COVID-19: increasing the need for prevention and access. Prev Chronic Dis. (2020) 17:200266. doi: 10.5888/pcd17.200266

15. Abuse S. Mental Health Services Administration. 2019 Key Substance Use and Mental Health Indicators in the United States: Results from the 2018 National Survey on Drug Use and Health (HHS Publication No. PEP19-5068, NSDUH Series H-54). Rockville, MD: Center for Behavioral Health Statistics and Quality. Substance Abuse and Mental Health Services Administration (2019). Available online at: https://www samhsa gov/data

16. Kessler RC, Avenevoli S, Costello EJ, Georgiades K, Green JG, Gruber MJ, et al. Prevalence, persistence, and sociodemographic correlates of DSM-IV disorders in the National Comorbidity Survey Replication Adolescent Supplement. Arch General Psychiatry. (2012) 69:372-80. doi: 10.1001/archgenpsychiatry.2011.160

17. Hakeberg M, Boman UW. Self-reported oral and general health in relation to socioeconomic position. BMC Public Health. (2018) 18:18. doi: 10.1186/s12889-017-4609-9 
18. Li KY, Okunseri CE, McGrath C, Wong MC. Self-reported general and oral health in adults in the United States: NHANES 1999-2014. Clin Cosmetic Investigational Dentistry. (2019) 11:399. doi: 10.2147/CCIDE.S234335

19. Adunola F, Garcia I, Iafolla T, Boroumand S, Silveira ML, Adesanya M, et al. Self-perceived oral health, normative need, and dental services utilization among dentate adults in the United States: National Health and Nutrition Examination Survey (NHANES) 2011-2014. J Public Health Dentistry. (2019) 79:79-90. doi: 10.1111/jphd.12300

20. Guo Y, Logan HL, Dodd VJ, Muller KE, Marks JG, Riley III JL. Health literacy: a pathway to better oral health. Am J Public Health. (2014) 104:e85e91. doi: 10.2105/AJPH.2014.301930

21. Persson K, Axtelius B, Söderfeldt B, Östman M. Oral health-related quality of life and dental status in an outpatient psychiatric population: a multivariate approach. Int J Mental Health Nurs. (2010) 19:6270. doi: 10.1111/j.1447-0349.2009.00639.x

22. Slack-Smith L, Hearn L, Scrine C, Durey A. Barriers and enablers for oral health care for people affected by mental health disorders. Austral Dental J. (2017) 62:6-13. doi: 10.1111/adj.12429

23. van der Zande MM, Exley C, Wilson SA, Harris RV. Disentangling a web of causation: an ethnographic study of interlinked patient barriers to planned dental visiting, and strategies to overcome them. Commun Dentistry Oral Epidemiol. (2021) 49:144-57. doi: 10.1111/cdoe.12586

24. McKibbin CL, Kitchen-Andren KA, Lee AA, Wykes TL, Bourassa K.A. Oral health in adults with serious mental illness: needs for and perspectives on care. Commun Mental Health J. (2015) 51:222-8. doi: 10.1007/s10597-014-9 758-z

25. Brigg N, Patterson S, Pradhan A. Enabling people with severe mental illness to overcome barriers to access dental treatment: a qualitative study applying COM-B framework analysis. J Mental Health. (2020). doi: 10.1080/09638237.2020.1803230. [Epub ahead of print].

Conflict of Interest: The authors declare that the research was conducted in the absence of any commercial or financial relationships that could be construed as a potential conflict of interest.

Publisher's Note: All claims expressed in this article are solely those of the authors and do not necessarily represent those of their affiliated organizations, or those of the publisher, the editors and the reviewers. Any product that may be evaluated in this article, or claim that may be made by its manufacturer, is not guaranteed or endorsed by the publisher.

Copyright (c) 2022 Tiwari, Kelly, Randall, Tranby and Franstve-Hawley. This is an open-access article distributed under the terms of the Creative Commons Attribution License (CC BY). The use, distribution or reproduction in other forums is permitted, provided the original author(s) and the copyright owner(s) are credited and that the original publication in this journal is cited, in accordance with accepted academic practice. No use, distribution or reproduction is permitted which does not comply with these terms. 